\title{
One-Dimensional Velocity Model for Ife Seismic Station from Inversion of Teleseismic P-wave Travel time Data
}

\author{
${ }^{1}$ Yakubu, T. A., ${ }^{2}$ Dewu, B. M. B., ${ }^{3}$ Lawal, K. M. ${ }^{3}$ Sule, P and ${ }^{4}$ Oniku, S. A. \\ ${ }^{1}$ Center for Geodesy and Geodynamics, Toro \\ ${ }^{2}$ Center for Energy Research and Training, Zaria \\ ${ }^{3}$ Department of Physics, Ahmadu Bello University, Zaria \\ ${ }^{4}$ Department of Physics, Modibbo Adama University of Tech., Yola.
}

\begin{abstract}
A One-Dimensional inversion of $\mathrm{P}$-wave travel time data observed at IFE seismic station between July 2009 when it was installed and July 2011 was carried out with the aim of obtaining the velocity model for the station region. The approach was based on fitting a series of straight lines to the travel time data. The results obtained showed that the P-wave velocity varies between 8.5 $\mathrm{km} / \mathrm{s}$ and $12 \mathrm{~km} / \mathrm{s}$, which indicates that all the seismic rays' bottom and had their turning point in the mantle. The plot of the velocity-depth profile reveals a three layer mantle with a transition at a depth of about $700 \mathrm{~km}$ corresponding to the transition between the upper and the lower mantle.
\end{abstract}

Keywords: P-wave, inversion, upper mantle, IFE station.

\section{INTRODUCTION}

Recent review of earthquake occurrences and observations in Nigeria had given rise to the establishment of the Nigerian National Network of Seismological stations. These stations are maintained by the Center for Geodesy and Geodynamics (C. G. G.), Toro, Bauchi state, Nigeria and of the ten proposed stations only five are currently operational (Fig.1). These stations, equipped with 24-bit 4-channel data acquisition system and broadband EENTEC seismometers became operational in 2009. Except for some teething problems experienced at some of the stations, the stations had continuously monitor earthquake at both regional and teleseismic distances since installation. This research is intended to carry out a 1-D velocity inversion of the travel time data obtained at one of the stations at Obafemi Awolowo University, lle- Ife, otherwise known as IFE station. Our approach is based on fitting a series of straight lines to the travel time curve (Shearer, 1999). The slope of each line determines a seismic velocity. It therefore become straight forward to invert the data for a simple model consisting of a small number of homogeneous layers

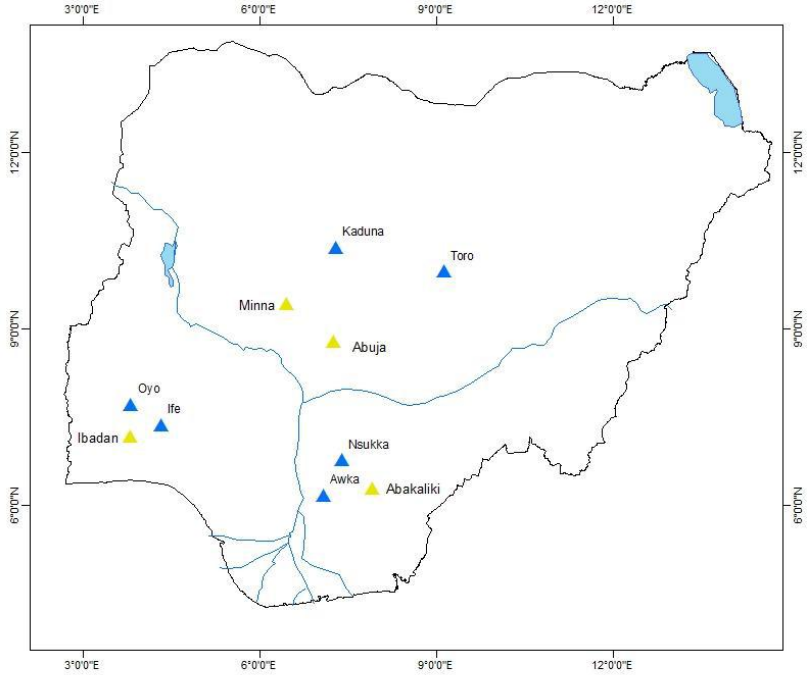

Legend

A Proposed Seismographic Stations

A Installed Stations with equipment

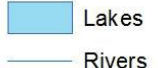

Fig. 1: Distribution of Seismographic stations in Nigeria

Geology and Tectonics of the Study Area: lle-Ife is located within the southwestern Nigeria basement complex in the equatorial rain forest of Africa (Fig.2). The main lithologies include the amphibolites, migmatite gneisses, granites and pegmatites. Other 
important rock units are the schists, made up of biotite schist, quartzite schist, talk-tremolite schist, and the muscovite schists. The crystalline rocks intruded into these schistose rocks. The amphibolite and the hornblende gneiss are the mafic and intermediate rocks in southwestern Nigeria. In Ilesha and Ile-Ife areas these amphibolites occur as low lying outcrops and most are seen in riverbeds while, the hornblende gneiss crops out at Igangan, Aiyetoro and Ifewara, along lle-lfe road as low lying hills in southwestern Nigeria. The hornblende gneiss is highly foliated, folded and faulted in places.

The magmatite-gnessic complex which constitutes over $75 \%$ of the surface area of the southwestern Nigerian basement complex is said to have evolved through 3 major geotectonic events:

$>$ Initiation of crust forming process during the Early Proterozoic (2000Ma) typified by the Ibadan (Southwestern Nigeria) grey gneisses considered by Woakes et al; (1987) as to have been derived directly from the mantle.

$>$ Emplacement of granites in Early Proterozoic (2000Ma) and

$>$ The Pan African events (450Ma-750Ma).

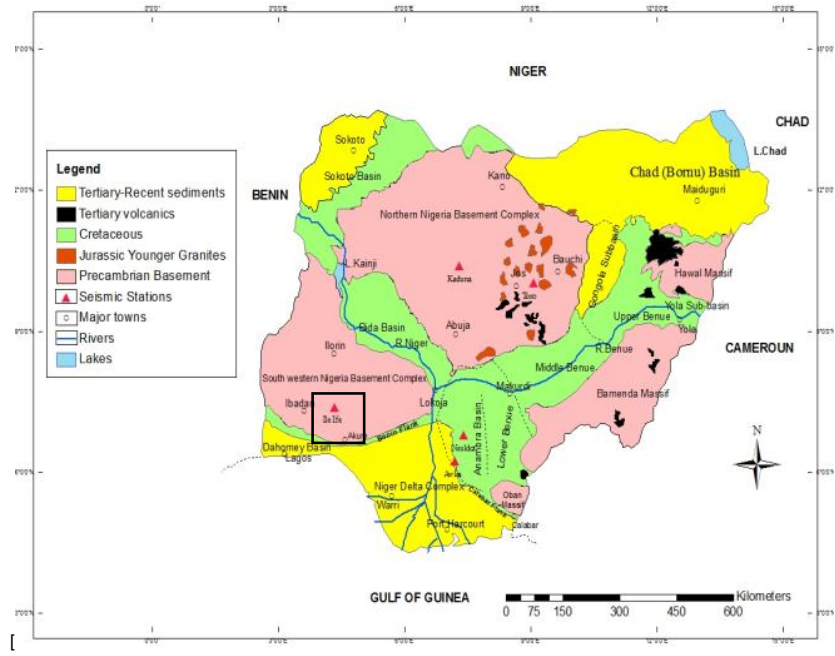

Fig.2: Geological Map of Nigeria showing the study area (box)

Data Acquisition: The data set used in this study, consisted of all reporting seismic events from July, 2009 to July 2012. The station is maintained among other stations by the Centre for Geodesy and Geodynamics, Toro, Bauchi state referred to as the Nigerian National Network of seismic stations. The stations are equipped with 24-bit multi-channel broadband recorders, and 30 seconds period seismometer. The data acquired by the equipment at the stations are recorded in the Miniseed format developed by Incorporated Research Institutions for Seismology (IRIS) at a sampling rate of 40 samples per second (sps). The data was analyzed using the SEISAN earthquake analysis software. The first arrival times corresponding to $\mathrm{P}$-waves used for this study were picked from the seismograms obtained from the recorded events. Other phases picked are available at the centre.

Other information such as the origin time of event, the theoretical/calculated travel time, epicentral distances, and azimuth were calculated using the travel time calculator (neic.usgs.gov/cgibin/tt/compute_tt.cg). The calculator is based on IASP91 velocity model.

The travel time data for all the events was obtained by subtracting the origin time (time of occurrence) $T_{0}$, of event from the observed arrival time $T_{a}$, of the event at the station, given by equation 1 :

$\mathrm{t}_{\mathrm{o}}=\mathrm{T}_{\mathrm{a}}-\mathrm{T}_{\mathrm{o}}$

\section{RESULTS}

All the events used in this research work consisted of about 109 events carefully selected from the seismograms recorded at the station for the period July 2009 to July 2011. The events are in the epicentral distance range of $0<29^{\circ}<180^{\circ}$, hence all the events are at teleseismic distances. The events location on a world map centered on IFE is shown in Fig.3, the plot is limited to epicentral distance $96^{\circ}$. Each concentric ring represents an increment of 20 degree in epicentral distance. The plot of the arrival times versus the epicentral distance in degree for events reporting at the station is shown in Fig. 4.

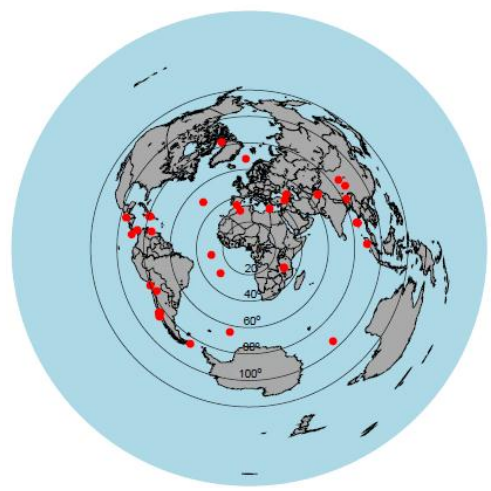

Fig.3: Events Location Centered on Ife Station 


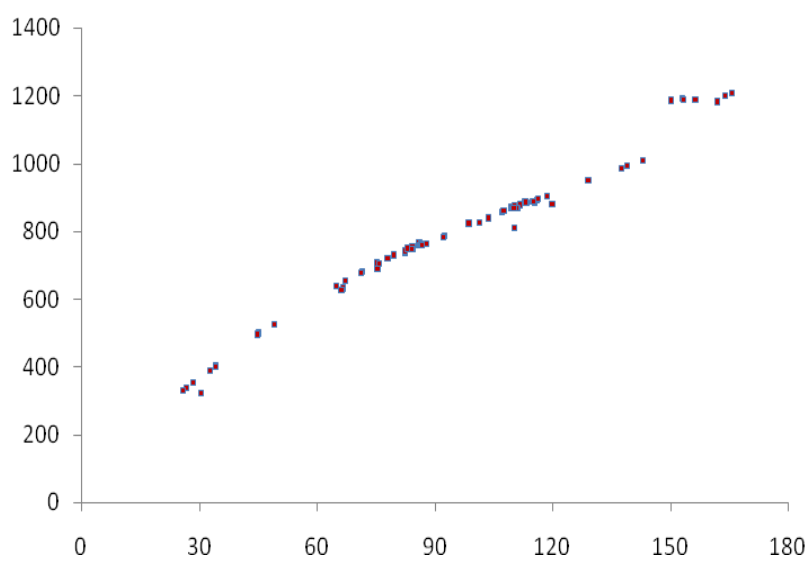

Fig.4: Travel time versus epicentral distance plot for IFE station

The observed travel time data form a discrete set of points from which it is required to find the $V-Z$ plane ( $V$ being the velocity and $Z$ the depth). We now examine the case where from the observations and whish to invert for a velocity structure that can explain the data; this is referred to as the reverse problem. Typical strategy to solving an inverse problem includes, finding an average 1-D velocity-depth function, this was done by fitting a series of straight lines to our travel time $\mathrm{T}(\mathrm{X})$ curve Fig.4 as shown in Fig. 5. The travel time data were fitted with three straight line segments leading to model containing three homogeneous layers. The slope and the intercept were then estimated.

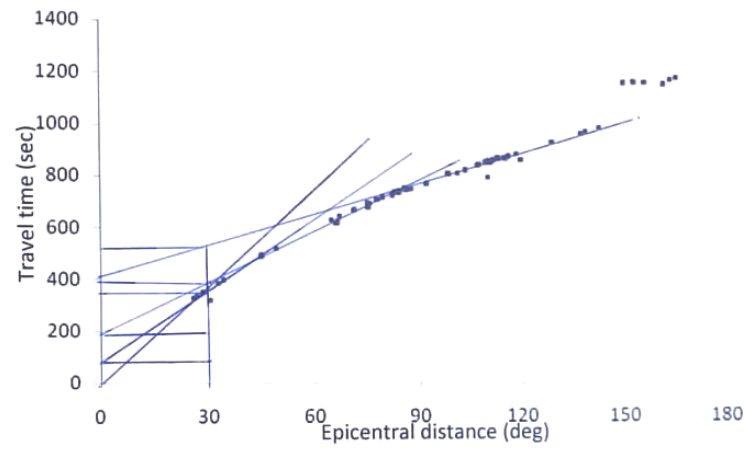

Fig.5: Series of straight line fittings on Travel time curve of IFE station

A Fortran 77 program which performs the inversion of the travel time data was written based on the $T(p)$ equation (2). The velocity depth model obtained for the station is shown in Fig.6.

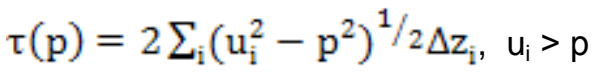

Where, $T(p)$ is the delay time,

$u$ is the slowness factor

$p$ is the ray parameter $=$ slope of the travel time curve $(\mathrm{dT} / \mathrm{dX})$

Note that at $\mathrm{T}_{1}=0$ the slowness $\left(\mathrm{u}_{1}\right)$ of the top layer is determined by the slope $\left(p_{1}\right)$ of the first segment $\left(u_{1}=\right.$ $p_{1}$ ), the slowness of the second layer is set by the slope of the second line segment $\left(u_{2}=p_{2}\right)$, etc.

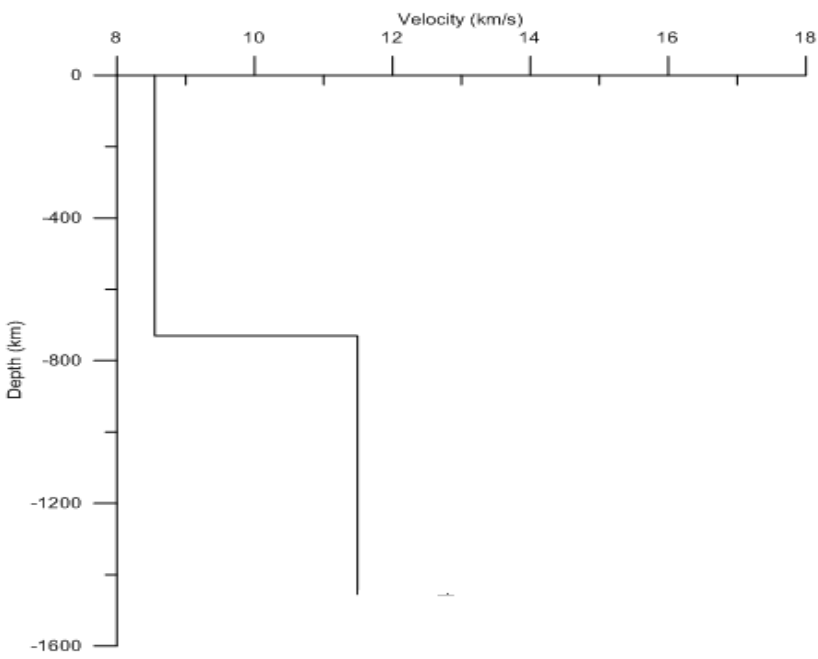

Fig.6: Mantle velocity - depth model for IFE station

\section{DISCUSSION OF RESULTS}

All the earthquakes reporting at the station are large earthquakes with body wave magnitude equal or greater than six (magnitudes $\geq 6$ ) and are at teleseismic distances. This implies that all the waves bottom and have their turning points in the mantle. The plot in Fig.3, show that the reporting events at the station are mainly from the world earthquake regions around the pacific margin, mid-ocean ridge and other world fracture zones (Shearer, 1999; Thorne and Terry, 1995). The plot of the travel time versus the epicentral distance shows that the $\mathrm{P}$ phases picked at the station are mainly $\mathrm{P}_{-}, \mathrm{P}_{\text {diff }}-$ and PKP- phases. The velocity model for the station shows a three layer mantle structure, with a transition at an average depth of about $720 \mathrm{~km}$., and the mantle velocity varying between $8.5 \mathrm{~km} / \mathrm{s}$ and 12.0 $\mathrm{km} / \mathrm{s}$. This is generally in agreement with mantle velocity model of Dziewonski and Anderson, (1981). 
Am. J. Sci. Ind. Res., 2013, 4(2): 210-213

\section{CONCLUSION}

This research work has shown that the quality of the data set observed at the station is good. The observed events are teleseismic, no events were observed within the local and regional distances. All the observed events have their turning points in the mantle hence the velocity varies between $8.5 \mathrm{~km} / \mathrm{s}$ and $12.0 \mathrm{~km} / \mathrm{s}$. The mantle velocity model shows a three layer mantle structure with an average transition thickness of about $720 \mathrm{~km}$.

\section{REFERENCE}

Dziewonski, A. M. and Anderson, D. L. (1981). Preliminary reference Earth model, Phys. Earth Planet. Inter., 25, 297-356.
Shearer, P.M. (1999). Introduction to seismology. Cambridge University Press, page 259

Thorne, L. and Wallace, C.T. (1995). Modern global seismology. Academic press. Page

535.

Woakes, M. Ajibade C.A., Rahaman, M.A., (1987): Some metallogenic features of the

Nigerian Basement, Jour. of Africa Science, 5, 655664.

http://neic.usgs.gov/cgi-bin/tt/compute tt.cg 